\title{
Action on the social determinants of health through social enterprise
}

\author{
Cite as: CMAJ 2017 March 20;189:E440-1. doi: 10.1503/cmaj.160864
}

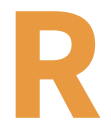

ecent attention to the role that social entrepreneurship could play in addressing acute health care challenges ${ }^{1}$ reminds us that addressing the socioenvironmental factors that influence the physical, mental, social and spiritual components of health and well-being ${ }^{2}$ requires similarly innovative and imaginative responses. Social enterprises are a potentially useful and economically viable strategy to this end. These are organizations that engage in commercial trade for a social purpose - most often to address one or more aspects of social vulnerability rather than for the personal financial enrichment of owners or shareholders.

Examples of Canadian social enterprises include Manitoba Green Retrofit, a social enterprise that takes on small construction projects, environmental retrofits and treatments for bedbug infestation in Winnipeg's low-income housing neighbourhoods, while at the same time providing job skills training and employment to local residents that creates a sense of place and community belonging; Parkdale Green Thumb Enterprises in Toronto, a horticulture business that employs people living with serious mental illness to design green spaces and provide groundskeeping services for nonprofit organizations, low-income housing, hospitals, the private sector and community groups; and Inside Art, a cooperative run by inmates at Mountain Institution in British Columbia, a medium security prison. By engaging incarcerated individuals in creating art and making business decisions about their cooperative business model, this social enterprise has helped persons excluded from society to contribute to correctional programming, learn new skills and build confidence.

\section{A WISE approach to health?}

Abundant "lay knowledge"3 exists that shows the influence that social enterprise can have on individual valorization, social capital and civic engagement of society's most disenfranchised, giving credence to the notion that social enterprise and social determinants of health. Most of the studies examined in that review focus on a particular type of social enterprise that aims to create employment for vulnerable people who are profoundly disadvantaged in accessing the mainstream labour market. This includes people who are chronically unemployed, leaving long-term institu-

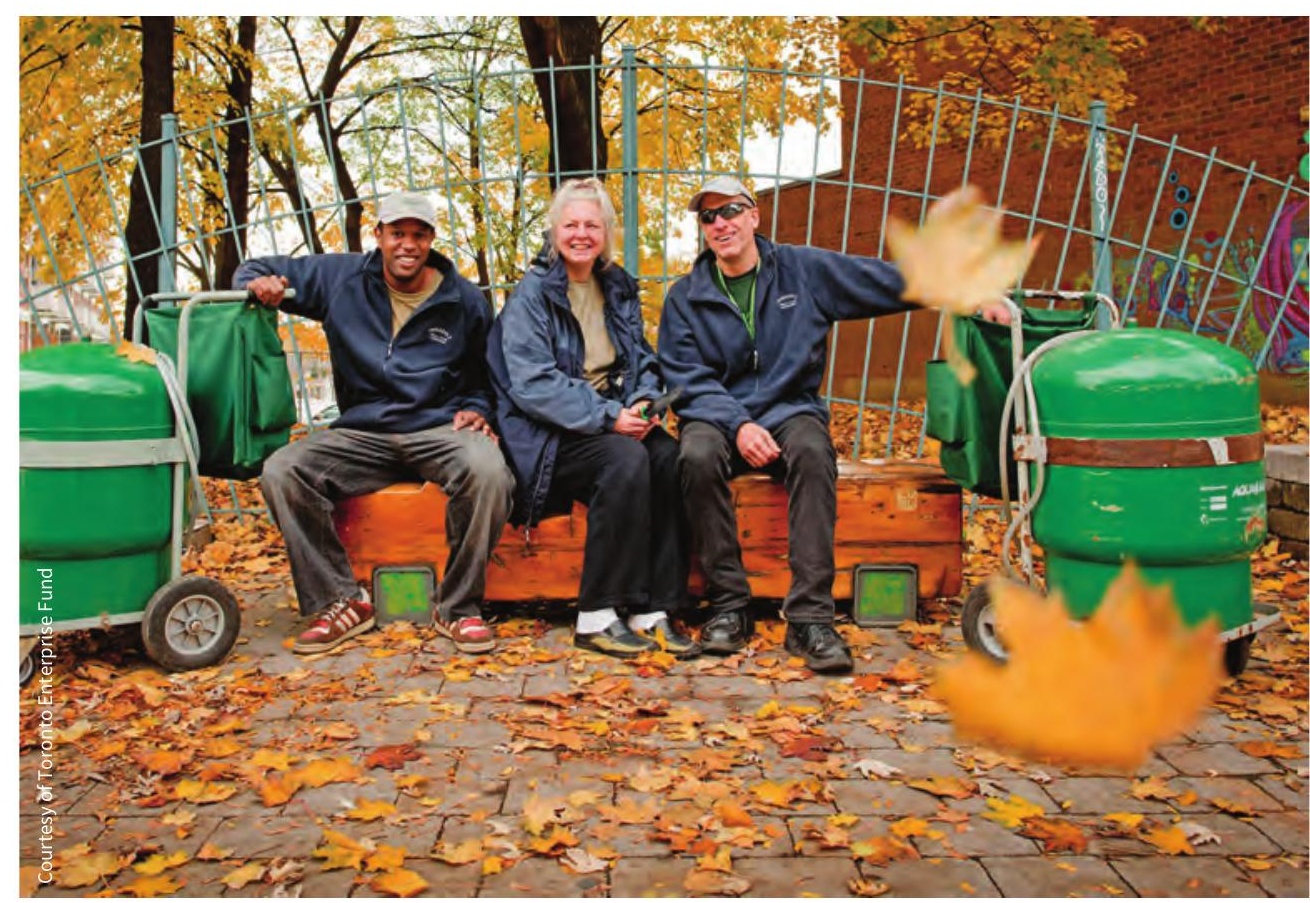

A few of the workers at Parkdale Green Thumb Enterprises.

entrepreneurship could potentially have an influence on the social determinants of health. ${ }^{4}$

A recent systematic review of social enterprise-led activity on health and wellbeing ${ }^{5}$ found evidence (albeit limited) of positive impacts on mental health, selfreliance/self-esteem and health behaviours, reductions in stigma and the building of social capital; all are important tional care, living with serious mental health issues, chronic health conditions or physical disabilities; in other words, factions of society that are most at risk for poor health outcomes and most likely to experience inequity in access to traditional health services. The focus of such "Work Integration Social Enterprises" (WISEs) is to provide transitional or permanent employment, and/or entrepreneurial 
opportunities in a supportive, empowering and community-based environment. ${ }^{6}$

One particular at-risk group of longstanding concern to both the health and welfare sectors is youth with mental health problems who live on the street. A traditional (pathogenic) approach to engaging with this group might address common presenting symptoms, such as injuries from physical violence or abuse, physical and emotional impacts of self-medication and abuse of illicit substances. Programs such as needle exchanges might seek to address individual risk factors and/or wider harm (including to society) from illegal or harmful behaviours. Although we are not criticizing such approaches, there is good evidence that a holistic, social enterprise-led approach to working with this population can deliver positive results, and prevent manifestation of such symptoms. For example, Ferguson ${ }^{7}$ described a social enterprise in which young people with mental illness living on the streets of Los Angeles were employed to design, manufacture and sell clothing items popular with youth. Their employment prospects and clinical outcomes were improved through peer mentoring, vocational training and training in small business skills, and integrated with the provision of clinical and harm reduction services.

\section{Challenges showing impact}

Despite many examples of good news, evidence to support that social enterprises such as WISEs do work (in particular, evidence that meets the standards that public health officials currently require) remains scarce. Assessing the health and well-being benefits of WISEs presents numerous challenges to researchers and to policy-makers. We have seen that randomized controlled trials - the gold standard in public health evaluation - are often unsuitable for a variety of reasons, including the expense, small sample sizes and ethical reasons relating to the types of populations that social enterprises traditionally work with. Although some promising groundwork has been laid to move this research agenda ahead in recent years, some key issues remain. For one, WISEs are highly idiosyncratic, often based upon population-specific needs and business-specific goals and visions. To date, there is a lack of agreement on core organizational, structural and process elements that define WISE, while respecting the need for business diversity across a range of business features such as the products/services offered, hiring practices, and level of involvement of the marginalized population in business development and operations. This variability, combined with the multiple health determinants that are affected by WISE participation, make this a highly complex intervention that must be carefully unpacked to better understand the causal pathways, and how the variables embedded in the social determinants can (potentially) be identified and measured in ways that are both valid and conceptually meaningful.

Therefore, there is a clear need to heighten theoretical understanding of how WISEs affect health and health equity; identify WISE business implementation processes and practices that contribute to population health and health equity; and advance this emerging field of scientific enquiry through identification of feasible research designs to meaningfully explore the impact of these enterprises on health and health equity. Application of realist evaluation principles ${ }^{8,9}$ may help guide scientific inquiry in this regard: supporting researchers to answer developmental-stage questions concerning the contextual factors that support positive outcomes, and the theoretical processes leading to change. Such a line of inquiry will help lay the groundwork necessary for future rigorous research on this highly complex form of intervention. Furthermore, we need to influence and encourage policy-makers and research funders to think imaginatively not only in terms of what actually constitutes a public health intervention, but also about how community-led activity could be better supported and integrated with traditional health service approaches to form a wider societal response to addressing the social determinants of health.

The public health contributions of those who work to address social vulnerabilities in their local communities, but who operate outside of formal health systems, deserve to be acknowledged and better understood if we are to address longstanding issues of public health concern.

\section{Michael J. Roy PhD}

Yunus Centre for Social Business and Health, Glasgow Caledonian University, Glasgow, UK

\section{Rosemary Lysaght PhD, Terry M. Krupa PhD}

School of Rehabilitation Therapy, Queen's University, Kingston, Ont.

\section{References}

1. Lim YW, Chia A. Social entrepreneurship: improving global health. JAMA 2016;315:2393-4.

2. Gewurtz RE, Moll SE, Letts LJ, et al. What you do every day matters: a new direction for health promotion. Can J Public Health 2016; 107:e205-8.

3. Popay J, Williams G, Thomas C, et al. Theorising inequalities in health: the place of lay knowledge. Sociol Health Illn 1998;20:619-44.

4. Roy MJ, Donaldson C, Baker R, et al. Social enterprise: New pathways to health and well-being? J Public Health Policy 2013;34:55-68.

5. Roy MJ, Donaldson C, Baker R, et al. The potential of social enterprise to enhance health and well-being: a model and systematic review. Soc Sci Med 2014;123:182-93.

6. Krupa TM, Lysaght R, Brown J, et al. Environmental scan of social businesses. In: The aspiring workforce - employment and income for people with serious mental illness. Ottawa: Mental Health Commission of Canada; 2013:46-70. Available: www.mentalhealthcommission.ca/English/ initiatives/11895/aspiring-workforce (accessed 2016 July 19).

7. Ferguson KM. Merging the fields of mental health and social enterprise: lessons from abroad and cumulative findings from research with homeless youths. Community Ment Health J 2012;48:490-502.

8. Pawson R, Tilley N. Realistic evaluation. Thousand Oaks (CA): Sage; 1997.

9. Fletcher A, Jamal F, Moore G, et al. Realist complex intervention science: applying realist principles across all phases of the Medical Research Council framework for developing and evaluating complex interventions. Evaluation (Lond) 2016;22:286-303.

This article has been peer reviewed.

This work was supported by the Medical Research Council, and the Economic and Social Research Council (grant no. MR/L003287/1). 